\title{
Structural Change In Models Of Migration Omission Of Psychic Income
}

\author{
STEPHen P. Coelen*
}

The question of the relative importance of various migration determinants has been raised in recent migration research. Some of the associated debate has resulted from the inevitable squabbling among the proponents of various disciplines over the variables of their own special interest - economic, sociologic, geographic, etc., but much of the debate has real substance and policy significance. From an economic perspective, if differential regional incomes and unemployment are less important migration determinants than individualistic and personal factors (like amenities and better quality of life), then migration does not have the important equilibrating quality so frequently attributed to it. Without migration to equalize factor prices, commodity trade and capital movements become strained as equilibrating factors and the conclusions of the neoclassical regional growth model, Borts and Stein [1964], are less likely to be obtained. In that case, national output would be suboptimized by regional concentrations of labor, and regional policy would have to become aimed at finding viable means of properly redistributing population. $^{1}$

Interest in assessing relative importance of the migration determinants is expressed in the interdisciplinary surveys of the literature on migration, like those of Shaw [1975] and Yap [1975]. Those two studies, in particular, are in marked contrast to one another. Yap reviews studies in the less developed countries, citing surveys which show economic factors to be the most frequent reason for migration. Yap argues, however, that (a) it is difficult to measure and analyze properly the noneconomic factors (urban services) which influence migration, (b) noneconomic factors seem to be less important than economic factors, and (c) there is little evidence to indicate that the relative importance of these migration factors will change in the near future, Yap [1975], pp. 13,20 , and 35 . Shaw similarly finds support that economic factors are strongly motivating reasons for migration, listed by 50 to 60 percent of the migrating population in response to surveys as the prime factor causing the move, Shaw [1975], p. 58. Yet, Shaw concludes from the evidence he presents:

\footnotetext{
*Assistant Professor of Economics, The Pennsylvania State University. I am indebted to Monroe Newman for helpful comments on an early draft of the paper and for funding for research to the Regional Analysis Center, The Pennsylvania State University.
} 
It may be that as an economy progresses toward an urban-industrialized state, the role of pecuniary considerations . . . decline in importance as a motive to migrate. Shaw [1975], p. 101.

Others, as well, have also evaluated the question of importance of migration determinants. Gallaway et al. [1967] conclude that non-economic factors are the predominant explanations. Sauli [1972], Liu [1975], Long and Hansen [1976] and Fuguitt and Zuiches [1975] argue that non-economic personal preferences are increasingly significant explanations of migration. Liu, as an example typical of the others, states:

Recently more and more people have been commenting on the paradoxes of affluence. Discontent with the quality of life seems to have increased proportionally with technological advance and growth in material wealth. Liu [1975], p. 9.

In this case, people move to obtain non-economic quality of life just as they had moved to increase material wealth.

The belief that the importance of determinants will shift over time as growth and development occur is the central theme of the mobility transition hypothesis, presented by Zelinsky [1970] and [1974]. As individuals' incomes increase in pace with the economic growth of their society, individuals migrate for non-economic reasons because increased incomes lower relative migration costs and make any given real increment to income (which might be obtained by migrating toward high income regions) seem less significant than it might have seemed when incomes were low. Other things constant, the non-economic factors become more important. Of a five-phase mobility transition, Zelinsky theorizes:

(in Phase IV there) is the emergence of non-economic motivations for both migrant and circulator; ... (in Phas V), it seems likely that non-economic considerations will loom even larger. Zelinsky [1970], p. 35.

The mobility transition or "determinants-shift" theory explains the apparent contrast between Shaw and Yap. Yap writing about migration in the LDC's deals with countries in which income levels are insufficient to permit non-economic factors to predominate. Shaw, writing more generally about migration in high income countries, observes non-economic determinants to be growing in importance because the income levels of the developed countries facilitate the expression of non-economic motivations.

This paper makes no attempt to deny the existence of "determinantsshift", but it does offer an alternative based on the belief that econometric misspecification in the earlier work has made the shifting importance of determinants more apparent than real. Under this alternative, either the importance of migration determinants have not changed at all or they have changed, but by less than has been alleged. Coelen, Groover and 
Heinz [1977] have demonstrated this case empirically, showing the effects of omitting demographic factors which describe migrant populations. The current paper extends this approach, postulating that some of the apparent decrease in marginal propensity to migrate to obtain higher income is due to the use of incompletely specified structural equations which leave out psychic costs and benefits (which have not ever been measurable) and, therefore, have been excluded from empirical work.

\section{Incomplete Specification of Migration Models}

Greenwood [1969] has already shown that omitting variables in migration models causes bias. He specifically considered the deletion of migrant stock which is an estimate of the flow of information from $j$, the destination, to $\mathrm{i}$, the origin. In conventional cases, deletion of migrant stock overestimates coefficients of variables when they are themselves autocorrelated. Greenwood's work is important because of the large amount of cross-sectional migration research that is done. Without considering migrant stock explicitly, the estimates that would be obtained are subject to bias.

The current work focuses on a similar but more implicit point. The psychic benefits (and costs) of origin and destination locations should influence the amount of migration (net and gross) that will occur between any two places, other variables constant. The problem is that psychic income is not measurable and the variable is deleted from empirical work with the result that uncertainty about the effect of psychic income abounds. In comparing migration studies on the same nation over time or among nations at the same time, variation of the impact of psychic income provides confusing information which is often mistaken as a shift in the structure of migration behavior.

Consider a study of net migration to place $\mathrm{i}$ from all places $\mathrm{j}, \mathrm{M}_{\mathrm{i}}={ }_{\mathrm{j}}^{\Sigma}$ $\left(M_{i j}-M_{j i}\right)$, in which $M_{i j}$ is the gross flow from $j$ to $i$. Assume that gross migration, $M_{i}$, to place $i$ is affected by regional levels of real money (per capita) income, $R_{i}$, psychic (per capita) income, $B_{i}$, and a catch-all factor, $\mathrm{Z}_{\mathrm{i}}$. The weighted average of the regional per capita incomes gives national average per capita income $R_{n}$. Psychic income is distributed with mean zero ${ }^{2} /$ and with elements $B_{i}$, positive and negative in the $i$ regions. We assume individuals migrate to relative total (psychic and money) income among regions such that one does not distinguish between the sources of his income. Then migration occurs according to:

$$
M_{i}=A\left(\frac{R_{f}+B_{i}}{R_{n}}\right)^{\alpha} Z_{i}^{\gamma} U_{i}
$$

in which $\mathrm{U}_{\mathrm{i}}$ is a random error. This can be restated as:

$$
\mathrm{M}_{\mathrm{i}}=\mathrm{A}\left(\mathrm{P}_{\mathrm{i}} \mathrm{Y}_{\mathrm{i}}\right)^{\alpha} \mathrm{Z}_{\mathrm{i}}^{\gamma} \mathrm{U}_{\mathrm{i}}
$$


with:

$$
P_{i}=\frac{B_{i}}{R_{i}}+1 \text { and } Y_{i}=\frac{R_{i}}{R_{n}}
$$

Because psychic income cannot be measured with convenience or accuracy, ${ }^{3}$ we are often left to evaluate migration with knowledge only of $Y_{i}$, the real income regional differential. Thus, the model we often fit is:

$$
\mathbf{M}_{\mathbf{i}}=\mathbf{A}^{\prime} \quad \mathrm{Y}_{1}^{\alpha} \quad \mathbf{Z}_{\mathrm{i}}^{\gamma} \quad \mathrm{U}_{\mathrm{i}}^{\prime}
$$

Denote deviation values of the log of these variables from the mean of their logs by small case letters and we have the estimated coefficient, $\widehat{\alpha}^{\prime}$ :

$$
\hat{\alpha}^{\prime}=\alpha+\alpha \Pi_{\mathrm{p}: s \mid \mathrm{z}}+\left(\frac{\sum \mathrm{uy} \sum \mathrm{z}^{2}-\sum \mathrm{yz} \sum \mathrm{uz}}{\sum \mathrm{y}^{2} \sum \mathrm{z}^{2}-\left(\sum \mathrm{yz}\right)^{2}}\right)
$$

with $\Pi_{\mathrm{p}: s} \mid \mathrm{z}$ the coefficient of $\mathrm{y}$ in regressing $\mathrm{p}$ on $\mathrm{y}$ in presence of $\mathrm{z}^{4}$ The expectation of $\left(\hat{\alpha}^{\prime}\right)$ is:

$$
\mathrm{E}\left(\widehat{\alpha}^{\prime}\right)=\alpha+\left.\alpha \pi_{\mathrm{p}: \mathrm{y}}\right|_{\mathrm{z}}
$$

This shows bias whenever $\left.\pi_{p: r}\right|_{x} \neq 0$. The coefficient is the expected value of the derivative, $d P_{i} / d Y_{i} \mid Z_{i}=\bar{Z}_{i}$, the partial of $p$ with respect to $y$ in a regression including $\mathrm{z}$.

It is the major purpose of this paper to evaluate such bias under the paradigm that the importance of $\mathrm{B}_{\mathrm{i}}$ declines over time with increases in $R_{n}$. This is equivalent to the belief that the psychic value of one's homestead becomes smaller and smaller as income, and the associated ease of migration (caused by higher incomes), rises. At a given point in time, we might, therefore, represent psychic income as:

$$
\frac{B_{1}}{R_{1}}=\psi\left(\frac{R_{1}}{R_{n}}\right)^{v} ; \psi, v>0 .
$$

In this case, psychic income varies over time with changes in $R_{n}$ and the associated variation in the $R_{i}$ around $R_{n}$.

Substituting (6) into the definition of $\mathrm{P}_{\mathrm{i}}$ from (2) and approximating $\left.\Pi_{p: y}\right|_{z}$ as the expectation of the derivative, $d P_{i} / d Y_{i}$, we can show that:

$$
\left.\Pi_{p: y}\right|_{z}=E\left(\frac{d P_{i}}{d Y_{i}}\right)=\psi v E\left\{\left(\frac{R_{i}}{R_{n}}\right)^{v-1}\right\}>0,
$$

since both $\psi, v>0$. The bias in $\hat{\alpha}^{\prime}$ is positive so that ignoring psychic income makes us overevaluate the propensity to migrate to higher income. $^{5}$ 


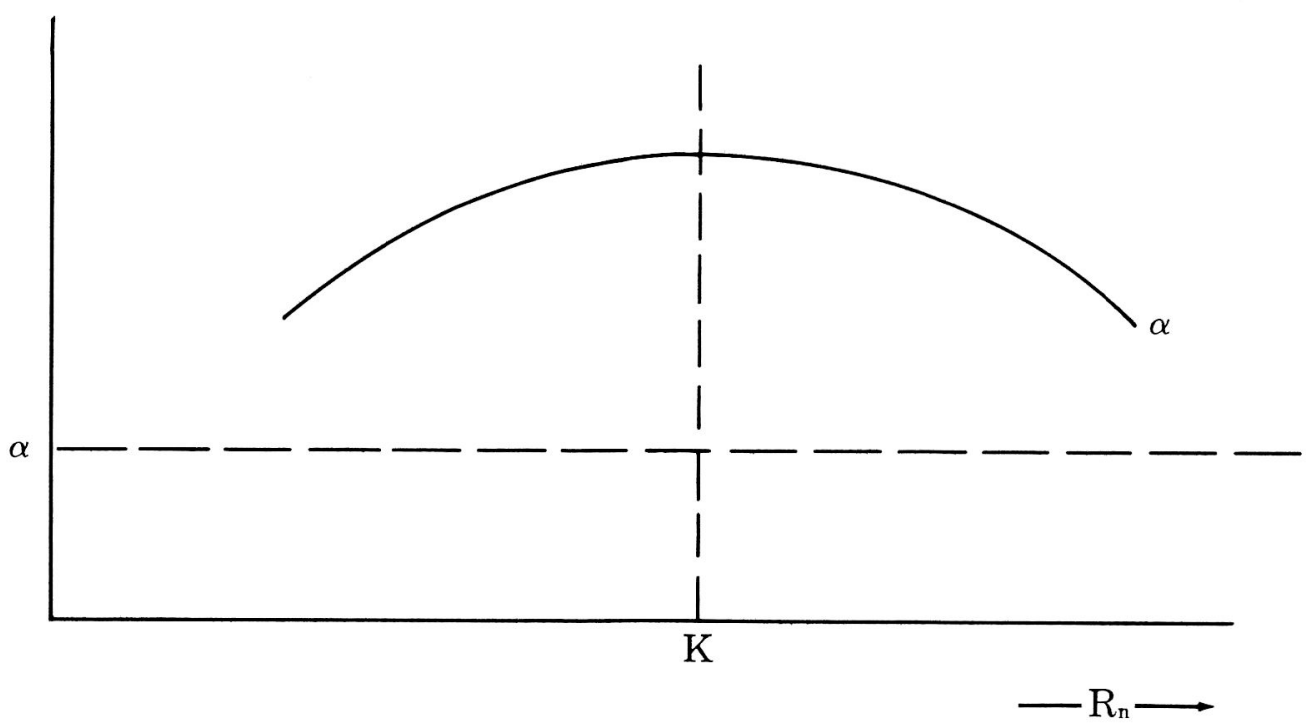

Figure 1: Estimated $\hat{\alpha}^{\cdot}$, under differing income conditions

The behavior of $\left.\pi_{\mathrm{n}: \mathrm{y}}\right|_{\pi}$ over time is of interest because it shows how our estimated coefficient, $\widehat{\alpha}^{-}$, will vary from the true parameter, $\alpha$. If $R_{n}$ increases, as typical, over time, we expect regional income divergence in the LDC's and regional income convergence in the developed countries, Williamson [1965]. This implies differing behavior of $\left.\pi_{\mathrm{r}: \mathrm{v}}\right|_{\mathrm{z}}$, dependent upon the parameters, especially $v$, such that $\frac{\left(\pi_{v}: r_{2}\right)}{\mathrm{dt}} \gtreqless 0$ in the LDC's as $v \gtreqless 1$ because the variance of $R_{i} / R_{n}$ rises with income divergence. It implies $\frac{\mathrm{d}\left(\pi_{\mathrm{p}}: r_{\mathrm{z}}\right)}{\mathrm{dt}} \gtreqless 0$ in the developed countries as $v \gtreqless 1$ because the variance of $R_{i} / R_{n}$ falls with income convergence. The result is a consistently biased estimate that may vary with the level of income and growth. One plausible case is shown in Figure 1 with $v>1$. At point $K$, roughly equivalent to Rostow's middle stage of economic growth, Rostow [1965], the estimated coefficient ceases to increase with the level of income and starts to decrease. We may be observing the latter portion of Figure 1 in developed countries and the earlier portion of Figure 1 in developing countries. This would cause us to believe that income determinants of migration are becoming increasingly less important in the developed countries, and increasingly more important in the developing countries.

\section{FOOTNOTES}

1 It is plausible that if migration occurs in response to sociological variables rather than economic, migration increases social welfare at a national level because of non-marketed factors influencing welfare. It is unlikely, however, that this case can lead to economic effi- ciency producing the most valued output with the given stock of productive factors.

Psychic income is the implicit sum of prices times characteristics of non-marketed goods and while with different price vectors, national average psychic income may be positive or 
negative, we can choose a numeraire in the utility maximization case for psychic income prices which will guarantee zero national average psychic income. The condition does little consequent harm.

${ }^{3}$ Much of the work of the Commission on the Third London Airport, e.g., A. A. Walters [1975], concentrates on consumers' surplus measurement in residential location.

$4 \hat{\alpha}^{\prime}=\frac{\Sigma \mathrm{z}^{2} \Sigma_{\mathrm{my}}-\Sigma \mathrm{yz} \Sigma \mathrm{mz}}{\Sigma \mathrm{y}^{2} \Sigma \mathrm{z}^{2}-(\Sigma \mathrm{yz})^{2}}$ from the normal equations and equation (4) is derived by substituting equation (2), expressed $m_{1}=$ $\alpha p_{1}+\alpha y_{1}+\gamma z_{1}+u_{1}$, assuming $y_{1}$ and $z_{1}$ to be independent.

This depends upon the form of the function used in equation (6), which in the text is quite general, chosen so that regional psychic income rises with increases in relative regional income while it falls with increases in national average per capita income, ceteris paribus. Whether psychic income increases or decreases from year to year depends on the value of parameter $\nu$ and the magnitude of the relative and national income changes.
This function is specific in the sense that it is one of a small class of functions which eases mathematical complexity. Any changes in $\mathrm{P}_{1}$ or $\mathrm{Y}_{1}$ can be traced to changes in $R_{1}$ and $R_{n}$ (exogenous to the model). The impact of equation (6) in deriving $d P_{1} / d Y_{1}$ is that the latter is independent of the specific source of variation of $d R_{1}$ or $d R_{n}$ because of the form of equation (6). Most other functions would have caused $\mathrm{dP}_{1} / \mathrm{dY}_{1}$ to vary depending on the changes in all of the individual regional incomes in the national distribution.

One referee suggested that psychic and money incomes are substitutes in a given location and that is an alternative plausible proposition. In that case, $B_{1}$ and $R_{1}$ would vary inversely and might look like $\mathrm{B}_{1} / \mathbf{R}_{1} \mu=$ $\Psi\left(\mathrm{R}_{1} / \mathrm{R}_{\mathrm{n}}\right)^{\nu}, \Psi, \nu>0 ;-\mu>\nu$. Then, $\mathrm{dP}_{1} /$ $\mathrm{dY}_{1}$ depends upon the source of variation and solution is more difficult, calling for simulation and yielding different solutions under different conditions. The basic point remains unchanged, however, bias occurs and fluctuates systematically over time.

\section{BIBLIOGRAPHY}

Borts, George and Jerome Stein, [1964]. Economic Growth in a Free Market, Columbia University Press, New York, New York.

Coelen, Stephen, Donald Groover and Kim Heinz, [1977]. "Specification Error Associated with Non-Constant Propensities to Migrate," mimeo, Regional Analysis Center, The Pennsylvania State University.

Fuguitt, Glenn and James Zuiches, [1975]. "Residential Preferences and Population Distribution," Demography, Vol. 12, pp. 491-504.

Greenwood, Michael J., [1969]. “An Analysis of the Determinants of Geographical Labor Mobility in the U.S.," Review of Economics and Statistics, Vol. 51, pp. 189-94.

Liu, B. C., [1975]. "Differential Net Migration Rates and the Quality of Life," Review of Economics and Statistics, Vol. 57, pp. 32937.

Long, Larry and Kristin Hansen, [1976]. "Models of Return, Repeat, and Primarily Migration by Age and Race," presented at Population Association of America, New York, New York.

Rostow, W. W., [1965]. The Stages of Economic Growth, Murray Printing Company. Massachusetts.
Sauli, H. I., [1972]. Effects of Metro-Area Attractiveness on Inter-Metropolitan Migration, Ph.D. dissertation, New York University.

Shaw, R. Paul, [1975]. Migration Theory and Fact, Regional Science Research Institute, Philadelphia.

Walters, A. A., [1975]. Noise and Prices, Clarendon Press, Oxford.

Williamson, J. G., [1965]. "Regional Inequality and the Process of National Development: A Description of the Patterns," Economic Development and Cultural Change, Vol. 13, pp. 3-45.

Yap, L. Y. L., [1975]. "Internal Migration in Less Developed Countries, A Survey of the Literature," International Bank for Reconstruction and Development, Staff Working Paper No. 215.

Zelinsky, Wilbur, [1970]. "The Hypothesis of the Mobility Transition," presented at the Population Association of America, Atlanta, Georgia.

Zelinsky, Wilbur, [1974]. "Selfward Bound? Personal Preferences and the Changing Map of American Society," Economic Geography, Vol. 50, pp. 144-59. 